\title{
Two-phase pressure drop prediction in helically coiled steam generators for nuclear power applications
}

DOI:

10.1016/j.ijheatmasstransfer.2016.05.027

\section{Document Version}

Accepted author manuscript

Link to publication record in Manchester Research Explorer

\section{Citation for published version (APA):}

Cioncolini, A., \& Santini, L. (2016). Two-phase pressure drop prediction in helically coiled steam generators for nuclear power applications. International Journal of Heat and Mass Transfer, 100, 825-834.

https://doi.org/10.1016/j.ijheatmasstransfer.2016.05.027

\section{Published in:}

International Journal of Heat and Mass Transfer

\section{Citing this paper}

Please note that where the full-text provided on Manchester Research Explorer is the Author Accepted Manuscript or Proof version this may differ from the final Published version. If citing, it is advised that you check and use the publisher's definitive version.

\section{General rights}

Copyright and moral rights for the publications made accessible in the Research Explorer are retained by the authors and/or other copyright owners and it is a condition of accessing publications that users recognise and abide by the legal requirements associated with these rights.

\section{Takedown policy}

If you believe that this document breaches copyright please refer to the University of Manchester's Takedown Procedures [http://man.ac.uk/04Y6Bo] or contact uml.scholarlycommunications@manchester.ac.uk providing relevant details, so we can investigate your claim.

\section{OPEN ACCESS}




\title{
Title
}

Two-phase pressure drop prediction in helically coiled steam generators for nuclear power applications

\section{Authors \& Affiliations}

Andrea Cioncolini [corresponding]

School of Mechanical, Aerospace and Civil Engineering, University of Manchester, George Begg Building, Sackville Street, M1 3BB Manchester, United Kingdom, Tel: +44.161.306.3711, e-mail: andrea.cioncolini@manchester.ac.uk

\section{Lorenzo Santini}

ENEL Ingegneria e Ricerca SpA, Via Mantova 24, 00198 Roma, Italy, Tel: +421.911.442.421, e-mail: lorenzo.santini@enel.com

\begin{abstract}
This study considers the prediction of the pressure gradient with water-steam two-phase flows through helically coiled steam generator tubes, focusing in particular on the operating conditions of low-medium pressure, low mass flux and low heat flux typical of once-through steam generators with in-tube boiling adopted in small modular nuclear reactor systems. Twenty-five widely used empirical correlations have been tested against an experimental pressure drop databank drawn together in this study containing 980 data points. Since no existing correlation is capable of collapsing and satisfactorily fitting the collected databank, a new pressure drop prediction method for helically coiled tubes is proposed. This new prediction method is very simple to implement, as it is based on the homogeneous flow model, is asymptotically consistent with straight tube twophase flows and is largely superior in accuracy to existing prediction methods (mean absolute error of $7.3 \%$, and 9 points out of 10 captured to within $\pm 15 \%$ ). The new prediction method is applicable for operating pressures in the range of 0.75-9.0 MPa, mass fluxes from $400 \mathrm{~kg} / \mathrm{m}^{2} \mathrm{~s}$ to $1191 \mathrm{~kg} / \mathrm{m}^{2} \mathrm{~s}$, heat fluxes up to $750 \mathrm{~kW} / \mathrm{m}^{2}$, tube diameters within 5-20 mm and coil to tube diameter ratio above 32.4. Curvature effects on the pressure gradient in helical coil two-phase flows can be significant, particularly with high velocity flows in tight curvature coils where the centrifugal force is intense.
\end{abstract}




\section{Keywords}

Helical coil; Pressure drop; Two-phase flow; Steam generator; Curvature effect; Small modular nuclear reactor;

\section{Introduction}

Helically coiled tubes are frequently used in once-through steam generators with in-tube boiling due to the several advantages they offer in comparison with conventional straight tubes. For example, helically coiled tubes provide a greater heat transfer area per unit volume, which makes them attractive in applications where high compactness is desired, such as marine propulsion and integral layout nuclear reactors. Besides, helically coiled tubes can easily accommodate thermal expansions, which make them particularly robust in transient and offnormal operation. Moreover, the radial accelerations induced by the helical path promote liquid droplets deentrainment from the vapor, thus keeping the tube internal surface wet to higher vapor qualities than in a straight pipe. As a consequence, the onset of dryout is delayed and the heat transfer effectiveness in the post dryout region is enhanced with respect to a straight pipe.

Building on the previous positive experience gained with advanced gas reactors and liquid metal fast reactors, helically coiled once-through steam generators with in-tube boiling are currently receiving a renewed interest, promoted by their frequent adoption in advanced small modular nuclear reactor systems (nuclear reactors with equivalent electric power output below $300 \mathrm{MW}$, according to the International Atomic Energy Agency [1]). Presently, there are about 50 different small modular nuclear reactor designs in various stages of development worldwide [2], including advanced water cooled reactors, liquid metal cooled reactors, high temperature gas cooled reactors, and molten salt reactors. The main advantages of small modular nuclear reactor systems with respect to conventional nuclear power stations include lower initial capital investment, enhanced passive safety, simplified design, proliferation resistance, greater flexibility of operation and capability to meet the smaller demand of power typical of emerging economies and developing countries [3,4]. Among the small modular nuclear reactor systems currently under development worldwide, the integral layout pressurized water reactors are the most mature designs and stand out for near- and mid-term commercial deployment. In integral layout pressurized water reactors, all the components usually associated with the primary circuit of a conventional pressurized water reactor are housed within a single reactor vessel, thus significantly reducing the likelihood of loss of coolant accidents and enhancing the primary circuit cooling capability in natural circulation. These designs combine well known technologies and several years of commercial operating experience accumulated with traditional pressurized water reactors, with novel components and innovative design features that 
significantly enhance the safety of the system [5]. Due to their compactness, heat transfer efficiency and low susceptibility to thermal expansions, helically coiled once-through steam generators with in-tube boiling are the preferred option for integral layout pressurized water nuclear reactors.

The accurate prediction of the pressure drop is crucial for a sound design and efficient operation of any twophase flow systems, particularly so with nuclear power plant steam generators that are one of the most expensive components of the power plant, whose longevity and efficient operation are essential to profitable power production. In particular, the accurate prediction of the pressure gradient along the steam generator tubes is required to properly predict the temperature difference between the primary and the secondary fluid streams at the pinch point, which is one of the controlling parameters in the steam generator sizing. Notably, the emphasis on compactness that characterizes integral layout nuclear power plants makes the accurate prediction of the temperature difference at the pinch point crucial for a sound system design. Moreover, it is well known that once-through steam generators with in-tube boiling are vulnerable to undesired flow-pressure oscillations. The most efficient way to control these undesired oscillations is to apply orifices at the inlet of the steam generator tubes. The precise knowledge of the tube side pressure drop is a prerequisite for a sound design of the orifices to achieve stable flow conditions while avoiding overdesign that would result in a corresponding overdesign of the feed-water pump, thus eroding the system profitability.

Due to its practical relevance, two-phase flow pressure drop in helically coiled tubes has been investigated quite extensively [6-23]. Notably, several authors found straight tube prediction methods appropriate to predict the pressure drop in helical coils. In particular, the straight tube methods of Lockhart and Martinelli [24] and of Martinelli and Nelson [25] have been frequently reported to satisfactorily extrapolate to helically coiled tubes. Unfortunately, however, no systematic assessment of straight tube pressure drop correlations for use with helical coils has been conducted at present. Moreover, straight tube correlations have been invariably modified for use with helical coils by replacing the single-phase straight tube friction factor expressions of the original formulations with single-phase friction factor correlations specific for helical coils. This is normally a minor modification, as in turbulent flow conditions the difference in the friction factor between a straight tube and a helical coil is normally on the order of $10-20 \%$. Nonetheless, this modification somewhat obscures the actual accuracy of existing straight tube pressure drop prediction methods when extrapolated to helical coils. What is worse, when modifying straight tube correlations for use with helical coils, different authors picked different single-phase friction factor correlations for helical coils, so that even comparing the results of different researches is rather difficult. Notably, some authors proposed pressure drop prediction methods specifically 
designed for helically coiled tubes $[11,12,19,20,23,26]$. None of these methods, however, is based on a large and diversified experimental databank, so that their applicability and accuracy in general design applications outside the operating conditions covered in the respective underlying databanks is unclear at the moment.

The cornerstone of the present study is the prediction of the two-phase pressure drop of water-steam flows in helically coiled tubes, focusing in particular on the operating conditions of low-medium pressure (1-8 MPa), low mass flux (200-1000 kg/m $\left.{ }^{2} \mathrm{~s}\right)$ and low heat flux $\left(100-500 \mathrm{~kW} / \mathrm{m}^{2}\right)$ typical of the operation of the once-through steam generators with in-tube boiling used in small modular nuclear reactor systems. First, an experimental pressure drop databank put together with literature data is used to provide an extensive and critical assessment of existing pressure drop correlations: 19 widely used straight tube correlations and 6 more prediction methods specifically derived for helical coils. Then, a new pressure drop prediction method for water-steam flow in helically coiled tubes is proposed. This new prediction method is very simple to implement, as it is based on the homogeneous flow model, is asymptotically consistent with straight tube two-phase flows and is largely superior in accuracy to existing prediction methods. The present study is part of a wide research program addressing single and two-phase boiling flows in helically coiled tubes, focusing in particular on the design and operation of compact once-through steam generators with in-tube boiling for nuclear power applications, notably small modular units $[22,23,27-31]$.

\section{Experimental pressure drop databank}

The main details of the experimental pressure drop databank collected from the open literature for use here are summarized in Table 1, while a selection of histograms that further describes the collected data is shown in Fig. 1. Even though the pressure drop in water-steam flows through helical coils has been studied quite extensively [6,8,11-13,19,20,22,23], only Zhao et al. [20] and Santini et al. [23] provide accurate pressure drop data in usable form. In particular, Zhao et al. [20] tested an electrically heated helical coil with a tube diameter of 9.0 $\mathrm{mm}$ and a coil diameter of $292 \mathrm{~mm}$, corresponding to a coil to tube diameter ratio of $D / d=32.4$. Their test section was $1.38 \mathrm{~m}$ long, was equipped with two pressure taps at the inlet and outlet to measure the pressure drop and was fed with two-phase flow generated in a preheater located upstream of the test section. On the other hand, Santini et al. [23] made experiments with an electrically heated helical coil with a tube diameter of $12.49 \mathrm{~mm}$ and a coil diameter of $1.0 \mathrm{~m}$, corresponding to a coil to tube diameter ratio of $D / d=80.1$ (note that in their study Santini et al. [23] used the tube nominal diameter of $12.53 \mathrm{~mm}$ to calculate the coil to tube diameter ratio, yielding $D / d=79.8$, whereas in the present study the measured tube diameter value of $12.49 \mathrm{~mm}$ is used instead, 
yielding $D / d=80.1$; the difference between the two values of the coil to tube diameter ratio is however negligible for practical applications). Their test section was $32 \mathrm{~m}$ long, was fed with subcooled liquid and was provided with nine pressure taps evenly distributed along the test section length to measure the pressure drop. For what concerns the other literature studies on water-steam pressure drop in helical coils $[6,8,11-13,19,22]$, the data are either provided in non-usable form, i.e. missing information in reporting the data, or only provide global pressure drop measurements generated with mock-up test sections that include a subcooled liquid region at the inlet and a superheated steam region at the outlet. The total pressure drop across these integral test facilities depends on the location along the channel of the onset of nucleate boiling and of the dryout, but these are not experimentally resolved. Therefore, these data are of little use in deriving or checking a pressure drop prediction method due to the errors in empirically locating the onset of nucleate boiling and the dryout, and errors in estimating the singlephase components of the total pressure drop, while remain valid to check system computer codes. It is evident that the available pressure drop data in usable form on water-steam flows through helically coiled tubes are rather limited, so that more experimental studies are clearly welcome. Since the present study is specifically targeting water-steam two-phase flows, available data generated with fluids other than water-steam $[7,9,10,14-$ $18,21]$ are not taken into account.

As can be noticed in Table 1, the collected experimental databank includes straight tube data as well, in addition to helical coils data. In particular, these straight tube data were generated with adiabatic water-steam flows in vertical tubes [32-34], covering the operating conditions of low-medium pressure and low mass flux of interest here. It is evident that a straight tube is the asymptotic configuration that a helical coil attains in the limit of the coil diameter diverging to infinity, i.e. for $D \rightarrow+\infty$, corresponding to a coil to tube diameter ratio $D / d \rightarrow+\infty$. As such, comparing helically coiled tube data with straight tube data generated at similar operating conditions allows a better resolution of the curvature effects on the two-phase pressure drop in helical coils. This is particularly important in the present case, as the available data for helical coils are limited and curvature effects have not been sistematically investigated in one experiment at present. The collected databank in Table 1, therefore, includes measurements taken with a tight curvature helical coil (Zhao et al. [20], D/d=32.4), measurements taken with a medium curvature helical coil (Santini et al. [23], $D / d=80.1$ ), and straight tube data that correspond to $D / d \rightarrow+\infty$, thus properly covering the coil to tube diameter ratio values of interest in practical applications. Overall, the collected databank contains 980 data points: 659 data points for helical coils and 321 data points for straight tubes. 
As can be noticed in Table 1, part of the collected data has been generated in adiabatic flow conditions, while part of the data has been generated during evaporation with electrically heated test sections. In these diabatic tests, in particular, the heat flux was uniform along the test section and all measurements were taken before the dryout. As shown by Zhao et al. [20], the effect of the heating on the two-phase pressure drop is negligible at the low heat fluxes of interest here, so that heating effects can be discarded in the present study, and data taken in adiabatic and evaporating flow conditions can be directly compared.

\section{Comparison with existing correlations}

The pressure drop data from Table 1 are compared in Figs. 2-7 with the predictions of 25 existing prediction methods: 19 straight tube empirical correlations and 6 more methods specifically designed for helical coils. The statistical comparison between data and predictions is reported in Table 2 . The straight tube correlations, in particular, include 12 different implementations of the homogeneous model (with two-phase viscosity defined according to McAdams et al. [35], Cicchitti at al. [36], Dukler et al. [37], Owens [38], Beattie and Whalley [39], Davidson et al. [40], Garcia et al. [41], Akers et al. [42] and Awad and Muzychka [43]), plus the widely used correlations of Lockhart and Martinelli [24], Martinelli and Nelson [25], Baroczy [44] and Chisholm [45], Friedel [46], Müller-Steinhagen and Heck [47], Lombardi and Carsana [48] and Shannak [49]. It is worth highlighting that all these straight tube correlations are used here in their original formulations, without any modifications or tailoring to better fit helical coils data. The correlations specifically derived for helical coils include the methods of Ünal et al. [12], Zhao et al. [20], Bi et al. [26], Guo et al. [19], Ruffel [11] and Santini et al. [23]. Notably, the correlations of Ünal et al. [12], Guo et al. [19] and Ruffel [11] are not asymptotically consistent with straight pipe flow, and therefore cannot be compared with the straight tube data collected in Table 1. Accordingly, the statistical comparisons and the figures for these correlations are limited to the helical coil data from Table 1. A comprehensive account of the straight tube correlations can be found in Thome and Cioncolini [50], while the helical coil correlations are described in Zhao et al. [20] and Santini et al. [23]. In particular, the method of Ünal et al. [12] is based on data generated with a tube diameter $d=18 \mathrm{~mm}$, a coil to tube diameter ratio in the range $D / d$ : 39-83, operating pressures of 14.9-20.1 MPa, and mass fluxes of 296-1829 $\mathrm{kg} / \mathrm{m}^{2} \mathrm{~s}$; the method of Guo et al. [19] is based on data generated with a tube diameter $d=10 \mathrm{~mm}$, a coil to tube diameter ratio in the range $D / d$ : $13-25$, operating pressures of $0.5-3.5 \mathrm{MPa}$, and mass fluxes of $150-1760 \mathrm{~kg} / \mathrm{m}^{2} \mathrm{~s}$; the method of Ruffel [11] is based on data generated with tube diameters of $d=10.7 \mathrm{~mm}$ and $d=18.6 \mathrm{~mm}$, a coil to tube diameter ratio in the range $D / d$ : 6.2-185, operating pressures of 6-18 MPa, and mass fluxes of 300-1800 
$\mathrm{kg} / \mathrm{m}^{2} \mathrm{~s}$. The prediction methods of Zhao et al. [20] and Santini et al. [23] are based on the parameter ranges summarized in Table 1.

Some of the pressure drop prediction methods considered here (Friedel [46], Müller-Steinhagen and Heck [47], Shannak [49], Ünal et al. [12], Zhao et al. [20], Bi et al. [26] and Guo et al. [19]) do not specify a void fraction correlation to calculate the acceleration and gravitational components of the total pressure gradient, thus leaving to the user the selection of a void faction correlation appropriate for his/her application. Available void fraction measurements in helical coils $[7,9,10,14,16,18]$ suggest that curvature effects on the void fraction are small and negligible, so that straight tube void fraction prediction methods can be extrapolated to helically coiled tubes, at least in first approximation. Therefore, the void fraction prediction method of Woldesemayat and Ghajar [51] was used here, as this is one of the most accurate general purpose void fraction correlations currently available for straight tubes [50]. Notably, with the databank in Table 1 the acceleration and gravitational components of the pressure gradient never account for more than $10-20 \%$ of the total pressure gradient, so that the void fraction prediction method used in the analysis has little impact on the final results.

From inspection of Table 2 and Figs. 2-7 it can be seen that no prediction method among those considered here satisfactorily fits the experimental databank in Table 1. Even though some correlations are statistically acceptable as a first approximation (notably, the methods of Martinelli and Nelson [25], Lombardi and Carsana [48] and Santini et al. [23], with mean absolute percentage errors within 20-25\%), the data displayed in Figs. 2-7 appear clearly clustered, so that no method successfully collapses the available data. The helical coil correlations, in particular, do not extrapolate outside the limits of their respective underlying databank. This is particularly evident with the methods of Zhao et al. [20] and Santini et al. [23], which fit very well the experimental data they were derived from, but clearly fail to collapse the rest of the experimental databank in Table 1. On the other hand, while the homogeneous model systematically underpredicts the entire databank, the other straight tube correlations are generally appropriate only for the straight tube data, while significantly underpredict the helical coils data. In particular, it is evident from Figs. 2-6 that the underprediction is inversely proportional to the coil to tube diameter ratio $D / d$, so that the tighter the helical coil the larger the underprediction. This clearly suggests that curvature effects are present, so that the tighter the helical coil curvature the higher the pressure gradient and the higher the underprediction of straight tube correlations. Even though the above indirect deduction of curvature effects on the pressure gradient in helical coils is no more than preliminary and evidently requires a direct experimental confirmation, this result is significant because it is in marked contrast with available data on convective boiling in helical coils. In particular, Santini et al. [31] 
measured the heat transfer coefficient during convective flow boiling in a full-scale helically coiled steam generator tube, prototypical of the once-through steam generators with in-tube boiling used in small modular nuclear reactor systems. Their experiments covered operating pressures in the range of 2-6 MPa, mass fluxes from 200 to $800 \mathrm{~kg} / \mathrm{m}^{2} \mathrm{~s}$ and heat fluxes from 40 to $230 \mathrm{~kW} / \mathrm{m}^{2}$ and clearly showed that curvature effects on the heat transfer coefficient below the dryout are small and negligible in practical applications. Remarkably, therefore, curvature effects on two-phase flow in helical coils are significant on the pressure gradient, while are small and negligible on the heat transfer coefficient during convective evaporation prior to the dryout. These markedly different curvature effects on the pressure drop and the heat transfer coefficient in helical coils can be qualitatively explained as follows. As shown in Fig. 1, the void fraction for the databank in Table 1 predicted according to the method of Woldesemayat and Ghajar [51] is in the range of 0.62-0.98, with the vast majority of the data above 0.8 . Such high values of the void fraction are normally associated with annular flow, which is the dominant flow pattern at low-medium operating pressures due to the relatively high specific volume of the vapor phase at these conditions. The main effects of the centrifugal force induced by the coil curvature on annular flow are to induce a thickening of the liquid film, due to the de-entrainment of liquid droplets from the vapor core, and to trigger the appearance of secondary recirculating flows in the liquid film, since the liquid film contains a boundary layer. The pressure gradient in annular two-phase flows strongly depends on the morphology of the liquid-vapor interface [52]. The thickening of the liquid film induced by the centrifugal force is likely to yield an enhanced waviness at the liquid-vapor interface, and this in turn could explain the observed increase of the pressure gradient with coil curvature. On the other hand, the heat transfer coefficient during convective evaporation depends on the transport of heat through the liquid film. Even though the turbulence structure in shear-driven annular liquid films is still largely unexplored [53-55], increased interfacial waviness and secondary recirculating flows can intuitively be expected to enhance the turbulence intensity in the liquid film, thus increasing the heat transfer effectiveness through the liquid film. This effect is however compensated by the thickening of the liquid film, which increases the liquid film thermal resistance. The compensation between enhanced turbulence intensity and thickening could explain the observed small sensitivity on coil curvature of the heat transfer coefficient during convective evaporation. It is worth highlighting that the above interpretation is no more than intuitive, though reasonable. A more solid physical explanation, which is not the subject of the present study, would clearly require a more fundamental analysis. The above discussion might give the wrong impression that helical coils are not convenient in practical two-phase flow applications involving in-tube flow boiling, as the pressure gradients are increased while the heat transfer coefficient is largely unaffected, with 
respect to straight pipes. On the contrary, as already discussed, one of the great advantages of helical coils is that the dryout is delayed with respect to a straight pipe, and the post dryout heat transfer is enhanced, so that the heat transfer effectiveness with in-tube flow boiling through helical coils is actually improved with respect to straight pipes where an enhancement is needed the most.

\section{New prediction method}

As discussed in the previous section, no pressure drop correlation among those considered here can be suggested for general use with helical coils, and there is a clear need to develop more accurate pressure drop prediction methods for helically coiled tubes. In what follows, therefore, a new correlating approach for the pressure gradient in helical coils is proposed. This new prediction method is based on the homogeneous model framework, so that the total pressure gradient is predicted as follows [50]:

$$
\frac{d P}{d z}=-2 f_{h} \frac{G^{2}}{\rho_{h} d}-G^{2} \frac{d}{d z}\left(\frac{1}{\rho_{h}}\right)-\rho_{h} g \sin (\vartheta)
$$

The three terms appearing on the right-hand side of Eq. (1) represent the frictional, the acceleration and the gravitational components of the total pressure gradient, respectively, where $f_{h}$ is the homogeneous Fanning friction factor, $G$ is the total mass flux, $d$ is the tube diameter, $\vartheta$ is the channel inclination angle with respect to the horizontal ( $\vartheta=0$ for horizontal flow, and positive angles denote upflow), $g$ is the acceleration of gravity and $z$ is the coordinate along the channel axis in the direction of the flow. The homogeneous density $\rho_{h}$ is calculated as follows:

$$
\rho_{h}=\left(\frac{1-x}{\rho_{l}}+\frac{x}{\rho_{g}}\right)^{-1}
$$

where $x$ is the vapor quality and $\rho_{l}$ and $\rho_{g}$ are the liquid and vapor densities. The homogeneous model is the simplest modelling framework available for channel two-phase flows, and this is the reason why it was selected for use here. It was felt that a simple and robust modelling approach was more suited for the limited data currently available, while more sophisticated approaches would be more appropriate for future developments, once more data will become available. Besides, the homogeneous model happens to be quite successful in the present context, as will be shown in the following, and it is already implemented in most two-phase flow computing codes. In the framework of the homogeneous model, two-phase flows are treated as a whole, neglecting the slip between the phases and representing the physical properties with average values. In principle, therefore, the homogeneous model should be particularly effective with two-phase flows characterized by a fine 
mixing of the phases, such as bubbly flows and mist flows, and less effective when the phases tend to become segregated and develop a slip, as happens with annular flows. As a matter of fact, however, it is well known that the homogeneous model can satisfactorily handle separated flows, provided that the homogeneous friction factor is properly defined. Treating separated two-phase flows with the homogeneous model is clearly an oversimplification, only justified when the homogeneous model provides accurate predictions of the pressure gradient for design applications. The homogeneous friction factor calculated for the databank in Table 1 is displayed in Fig. 8 versus the homogeneous Reynolds number $\mathrm{Re}_{h}$ defined as:

$$
\operatorname{Re}_{h}=\frac{G d}{\mu_{h}}
$$

where the homogeneous viscosity $\mu_{h}$ is calculated according to McAdams et al. [35]:

$$
\mu_{h}=\left(\frac{1-x}{\mu_{l}}+\frac{x}{\mu_{g}}\right)^{-1}
$$

Among the several expressions proposed to date for the homogeneous viscosity [50], the formulation in Eq. (4) was selected for use here because it is one of the simplest homogeneous viscosity expressions available, and is also formally consistent with the homogeneous density in Eq. (2). More complicated homogeneous viscosity expressions were tried but did not provide any significant gain in accuracy. For comparison, the single-phase friction factor expression of Filonenko [56] is also included in Fig. 8:

$$
f_{s f}=\left[1.58 \ln \left(\operatorname{Re}_{h}\right)-3.28\right]^{-2}
$$

As can be seen in Fig. 8, the homogeneous friction factor for the straight tube data decreases as the homogeneus Reynolds number increases with a trend that compares well with the single-phase expression in Eq. (5), even though the computed two-phase flow figures are about $60 \%$ higher than the corresponding single-phase ones. On the other hand, the homogeneous friction factor for the helical coils seems to be less dependent on the homogeneus Reynolds number, while it is clearly proportional to the tube to coil diameter ratio $d / D$ of the helical coil. Within the limits of the available data, therefore, the homogeneous friction factor $f_{h}$ depends on both the homogeneous Reynolds number $\mathrm{Re}_{h}$ and on the tube to coil diameter ratio $d / D$. In particular, as the tube to coil diameter ratio $d / D$ increases so does the friction factor, while the dependence of the friction factor on the Reynolds number weakens. It is worth noting that a qualitatively similar trend is observed with the friction factor for single-phase flow through rough circular tubes. As the wall roughness is gradually increased, in fact, the single-phase friction factor gradually loses its dependence on the Reynolds number, while becoming proportional to the dimensionless wall roughness. In analysing pressure gradient data in annular two-phase flow, 
the liquid film has frequently been treated as an equivalent wall roughness for the vapor core flow [57]. In this respect, the thickening of the liquid film induced by the centrifugal force is likely to yield an increase of this equivalent wall roughness for the vapor core flow, and this in turn could explain the observed trends of the friction factor in Fig. 8. The simple expression proposed here for the homogeneous friction factor is:

$$
f_{h}=\left\{2.916 \log _{10}\left[\frac{11.78}{\operatorname{Re}_{h}}+33.57\left(\frac{d}{D}\right)^{2.734}\right]\right\}^{-2}
$$

It is evident that the formal structure of Eq. (6) was borrowed from the theory of single-phase flow through circular rough tubes, where the dimensionless wall roughness was replaced with the tube to coil diameter ratio $d / D$, while the numerical parameters were fitted on the databank in Table 1. As can be seen in Fig. 8, Eq. (6) fits the available data quite well. The total pressure gradient predicted with the proposed new model, Eqs. (1) and (6), is compared with the measured data from Table 1 in Fig. 9, while the statistical comparison between predictions and measurements is provided in Table 2. As can be seen, the new prediction method collapses the available data pretty well, and with a mean absolute precentage error of $7.3 \%$ and 9 points out of 10 captured to within $\pm 15 \%$ this new method is significantly more accurate than the other correlations currently available. For a homogeneous Reynolds number in the range of $10^{5}$ to $10^{6}$, Eq. (6) predicts negligible curvature effects on the pressure gradient for a coil to tube diameter ratio $D / d$ above about 200, while the frictional pressure gradient in a tight helical coil with $D / d=30$ can be up to four times higher than in a straight tube. It is worth highlighting that the good fitting capability of the homogeneous model with the databank in Table 1 does not imply necessarily that these flows behave homogeneous, with the phases finely mixed and travelling at the same velocity through the channel. Rather, it only means that the homogenous model happens to contain enough physics to fit the data well, and provides accurate predictions of the total pressure drop for design applications.

As can be noticed, the new pressure drop prediction method incorporates the effect of the helical coil curvature (through the tube to coil diameter ratio $d / D$ ), but does not include the effects of the coil torsion or coil orientation with respect to gravity. Although these parameters are likely to have an effect on the fluid dynamics through helical coils, they cannot be resolved at present with the available data. As such, the new pressure drop prediction method proposed here should be regarded as a first approximation.

It is worth remembering that the new prediction method, Eqs. (1) and (6), is limited to water-steam flows at operating conditions of low-medium pressures, low mass fluxes and low heat fluxes of interest for the design and operation of once-through steam generators with in-tube boiling for small modular nuclear reactor systems. In particular, the new prediction method is applicable for water-steam flows at operating pressures in the range of 
0.75-9.0 MPa, mass fluxes from $400 \mathrm{~kg} / \mathrm{m}^{2} \mathrm{~s}$ to $1191 \mathrm{~kg} / \mathrm{m}^{2} \mathrm{~s}$, heat fluxes up to $750 \mathrm{~kW} / \mathrm{m} 2$, tube diameters within 5-20 $\mathrm{mm}$ and coil to tube diameter ratio above 32.4. Nonetheless, the new modelling approach proposed here may be used as a starting point for other operating conditions, as well as for fluids others than water-steam.

\section{Concluding remarks}

The performance of 25 empirical correlations for use in predicting two-phase pressure drops in helically coiled tubes was evaluated with respect to experimental data generated with water-steam flows. In particular, the collected data covered operating conditions of interest for the design and operation of coiled tube once-through steam generators with in-tube boiling for nuclear power applications, notably small modular advanced systems. No existing correlation was found successful in collapsing and predicting the available data. A new prediction method based on the homogeneous model framework was proposed for water-steam flows at operating pressures in the range of 0.75-9.0 MPa, mass fluxes from $400 \mathrm{~kg} / \mathrm{m}^{2} \mathrm{~s}$ to $1191 \mathrm{~kg} / \mathrm{m}^{2} \mathrm{~s}$, heat fluxes up to $750 \mathrm{~kW} / \mathrm{m} 2$, tube diameters within 5-20 $\mathrm{mm}$ and coil to tube diameter ratio above 32.4. This new method is asymptotically consistent with straight tube two-phase flows and is largely superior in accuracy to existing prediction methods. Based on the available data, the curvature effects on the pressure gradient in helical coil two-phase flows are significant, as the pressure drop in helical coils is increased with respect to straight pipes. On the other hand, curvature effects on the heat transfer coefficient during convective evaporation are small and negligible below the dryout, while the dryout is delayed and the post dryout heat transfer effectiveness is enhanced with respect to straight pipes. 


\section{Nomenclature}

$d \quad$ tube diameter $(\mathrm{m})$

D coil diameter (m)

$f_{h} \quad$ homogeneous Fanning friction factor (-)

$f_{s f} \quad$ single-phase Fanning friction factor (-)

$g \quad$ acceleration of gravity $\left(\mathrm{m} / \mathrm{s}^{2}\right)$

$G \quad$ mass flux $\left(\mathrm{kg} / \mathrm{m}^{2} \mathrm{~s}\right)$

$P \quad$ pressure $(\mathrm{Pa})$

$\mathrm{Re}_{h} \quad$ homogeneous Reynolds number (-)

$x \quad$ vapor quality (-)

$z \quad$ axial coordinate along channel (m)

$\mu_{g} \quad$ vapor viscosity $(\mathrm{kg} / \mathrm{ms})$

$\mu_{h} \quad$ homogeneous viscosity $(\mathrm{kg} / \mathrm{ms})$

$\mu_{l} \quad$ liquid viscosity $(\mathrm{kg} / \mathrm{ms})$

$\rho_{g} \quad$ vapor density $\left(\mathrm{kg} / \mathrm{m}^{3}\right)$

$\rho_{h} \quad$ homogeneous density $\left(\mathrm{kg} / \mathrm{m}^{3}\right)$

$\rho_{l} \quad$ liquid density $\left(\mathrm{kg} / \mathrm{m}^{3}\right)$

$\vartheta \quad$ channel inclination with respect to the horizontal (-) 


\section{References}

[1] IAEA, Innovative Small and Medium Sized Reactors: Design Features, Safety Approaches and R\&D Trends, Tech. Rep. IAEA-TECDOC-1451, International Atomic Energy Agency, 2005.

[2] IAEA, Advances in Small Modular Reactor Technology Developments. A supplement to: IAEA Advanced Reactor Information System (ARIS), International Atomic Energy Agency, 2014.

[3] H. Hidayatullah, S. Susyadi, M.H. Subki, Design and technology development for small modular reactors Safety expectations, prospects and impediments of their deployment, Prog. Nucl. Energ. 79 (2015) 127-135.

[4] M. Cooper, Small modular reactors and the future of nuclear power in the United States, Energy Res. Soc. Sci. 3 (2014) 161-177.

[5] Z. Liu, J. Fan, Technology readiness assessment of small modular reactor (SMR) designs, Prog. Nucl. Energ. 70 (2014) 20-28.

[6] A. Owhadi, K.J. Bell, B. Crain, Forced convection boiling inside helically-coiled tubes, Int. J. Heat Mass Transfer 11 (1968) 1779-1793.

[7] S. Banerjee, E. Rhodes, D.S Scott, Studies on cocurrent gas-liquid flow in helically coiled tubes, Can. J. Chem. Eng. 47 (1969) 445-453.

[8] M. Kozeki, H. Nariai, T. Furukawa, K. Kurosu, A study of helically coiled tube once-through steam generator, Bull. JSME 13 (1970) 1485-1494.

[9] K. Akagawa, T. Sakaguchi, M. Ueda, Study on gas-liquid two-phase flow in helically coiled tubes, Bull. JSME 14 (1971) 564-571. 
[10] G. Kasturi, J.B. Stepanek, Two-phase flow-I. Pressure drop and void fraction measurements in cocurrent gas-liquid flow in a coil, Chem. Eng. Sci 27 (1972) 1871-1880.

[11] A.E. Ruffel, The application of heat transfer and pressure drop data to the design of helical coil oncethrough boilers, Inst. Chem. Eng. Symp. Ser. 38 (1974) Paper 15.

[12] H.C. Ünal, M.L.G. van Gasselt, P.M. van't Verlaat, Dryout and two-phase flow pressure drop in sodium heated helically coiled steam generator tubes at elevated pressures, Int. J. Heat Mass Transfer 24 (1981) 285298.

[13] H. Nariai, M. Kobayashi, T. Matsuoka, Friction pressure drop and heat transfer coefficient of two-phase flow in helically coiled tube once-through steam generator for integral type marine water reactor, J. Nucl. Sci. Technol. 19 (1982) 936-947.

[14] K. Rangacharyulu, G.S. Davies, Pressure drop and holdup studies of air-liquid flow in helical coils, Chem. Eng. J. 29 (1984) 41-46.

[15] A.K. Saxena, A. Schumpe, K.D.P Nigam, W.D. Deckwer, Flow regimes, holdup and pressure drop for twophase flow in helical coils, Can. J. Chem. Eng. 68 (1990) 553-559.

[16] V. Czop, D. Barbier, S. Dong, Pressure drop, void fraction and shear stress measurements in an adiabatic two-phase flow in a coiled tube, Nucl. Eng. Des. 149 (1994) 323-333.

[17] A. Awwad, R.C Xin, Z.F. Dong, M.A. Ebadian, H.M. Soliman, Measurement and correlation of the pressure drop in air-water two-phase flow in horizontal helicoidal pipes, Int. J. Multiphase Flow 21 (1995) 607619.

[18] R.C Xin, A. Awwad, Z.F. Dong, M.A. Ebadian, An investigation and comparative study of the pressure drop in air-water two-phase flow in vertical helicoidal pipes, Int. J. Heat Mass Transfer 39 (1996) 735-743. 
[19] L. Guo, Z. Feng, X. Chen, An experimental investigation of the frictional pressure drop of steam-water twophase flow in helical coils, Int. J. Heat Mass Transfer 44 (2001) 2601-2610.

[20] L. Zhao, L. Guo, B. Bai, Y. Hou, X. Zhang, Convective boiling heat transfer and two-phase flow characteristics inside a small horizontal helically coiled tubing once-through steam generator, Int. J. Heat Mass Transfer 46 (2003) 4779-4788.

[21] S. Wongwises, M. Polsongkram, Evaporation heat transfer and pressure drop of HFC-134a in a helically coiled concentric tube-in-tube heat exchanger, Int. J. Heat Mass Transfer 49 (2006) 658-670.

[22] A. Cioncolini, L. Santini, M.E. Ricotti, Subcooled and saturated water flow boiling pressure drop in small diameter helical coils at low pressure, Exp. Therm. Fluid Sci. 32 (2008) 1301-1312.

[23] L. Santini, A. Cioncolini, C. Lombardi, M.E. Ricotti, Two-phase pressure drops in a helically coiled steam generator, Int. J. Heat Mass Transfer 51 (2008) 4296-4239.

[24] R.W. Lockhart, R.C. Martinelli, Proposed correlation of data for isothermal two-phase, two-component flow in pipes, Chem. Eng. Progr. 45 (1949) 39-48.

[25] R.C. Martinelli, D.B. Nelson, Prediction of pressure drop during forced-circulation boiling of water, Trans. ASME 70 (1948) 695-702.

[26] Q.C. Bi, T.K. Chen, Y.S. Luo, J.X. Zheng, J.G. Jing, Frictional pressure drop of steam-water two-phase flow in helical coils with small helix diameter, in: X.J. Chen et al. (Eds.), Proc. ${ }^{\text {rd }}$ Int. Symp. on Multiphase Flow and Heat Transfer, Vol. 1, Xi'an Jiaotong University Press and Begell House Inc., 1994, pp. 498-505.

[27] A. Cioncolini, L. Santini, An experimental investigation regarding the laminar to turbulent flow transition in helically coiled pipes, Exp. Therm. Fluid Sci. 30 (2006) 367-380. 
[28] A. Cioncolini, L. Santini, On the laminar to turbulent flow transition in diabatic helically coiled pipe flow, Exp. Therm. Fluid Sci. 30 (2006) 653-661.

[29] A. Cioncolini, L. Santini, M.E. Ricotti, Effects of dissolved air on subcooled and saturated flow boiling of water in a small diameter tube at low pressure, Exp. Therm. Fluid Sci. 32 (2007) 38-51.

[30] L. Santini, A. Cioncolini, C. Lombardi, M.E. Ricotti, Dryout occurrence in a helically coiled steam generator for nuclear power application, EPJ Web Conf. 67 (2014) 02102.

[31] L. Santini, A. Cioncolini, M.T. Butel, M.E. Ricotti, Flow boiling heat transfer in a helically coiled steam generator for nuclear power applications, Int. J. Heat Mass Transfer 92 (2016) 91-99.

[32] M. Silvestri, I. Casagrande, L. Cravarolo, A. Hassid, S. Bertoletti,C. Lombardi,G. Peterlongo,G. Soldaini, G. Vella, G. Perona, R. Sesini, A research program in two-phase flow, CISE Report, Segrate-Italy, 1963.

[33] G.P. Gaspari, C. Lombardi, G. Peterlongo, Pressure drops in steam-water mixtures, CISE Report R-83, Segrate-Italy, 1964.

[34] J. Würtz, An experimental and theoretical investigation of annular steam-water flow in tubes and annuli at 30 and 90 bar, Risø National Laboratory, Report No. 372, Denmark, 1978.

[35] W.H. McAdams, W.K Woods, L.C Heroman, Vaporization inside horizontal tubes II-benzene-oil mixtures, Trans. ASME 64 (1942) 193-200.

[36] A. Cicchitti, C. Lombardi, M. Silvestri, G. Soldaini, R. Zavattarelli, Two-phase cooling experimentspressure drop, heat transfer and burnout experiments, Energia Nucleare 7 (1960) 407-425.

[37] A.E. Dukler, M. Wicks, R.G Cleveland, Frictional pressure drop in two-phase flow, Part A: a comparison of existing correlations for pressure loss and holdup and Part B: an approach through similarity analysis, AIChE J. 10 (1964) 38-51. 
[38] W.L. Owens, Two-phase pressure gradient, ASME Int. Develop. Heat Transfer Part II (1961) 363-368.

[39] D.R.H. Beattie, P.B. Whalley, Simple two-phase frictional pressure drop calculation method, Int. J. Multiphase Flow 8 (1982) 83-87.

[40] W.F Davidson, P.H. Hardie, C.G.R. Humphreys, A.A. Markson, A.R. Mumford, T. Ravese, Studies of heat transmission through boiler tubing at pressures from 500 to 3000 Lbs, Trans. ASME 65 (1943) 553-591.

[41] F. Garcia, R. Garcia, J.C. Padrino, C. Mata, J.L. Trallero, D.D. Joseph, Power law and composite power law friction factor correlations for laminar and turbulent gas-liquid flow in horizontal pipelines, Int. J. Multiphase Flow 29 (2003) 1605-1624.

[42] W.W. Akers, H.A. Deans, O.K. Crosser, Condensing heat transfer within horizontal tubes, Chem. Eng. Prog. 54 (1958) 89-90.

[43] M.M. Awad, Y.S. Muzychka, Effective property models for homogeneous two-phase flows, Exp. Therm. Fluid Sci. 33 (2008) 106-113.

[44] C.J Baroczy, A systematic correlation for two-phase pressure drop, Chem. Eng. Prog. Symp. Ser. 62 (1966) 232-249

[45] D. Chisholm, Pressure drop due to friction during the flow of evaporating two-phase mixtures in smooth tubes and channels, Int. J. Heat Mass Transfer 16 (1973) 347-358.

[46] L. Friedel, Improved friction pressure drop correlation for horizontal and vertical two-phase pipe flow, European Two-Phase Flow Group Meeting, paper E2, Ispra, Italy, 1979.

[47] H. Müller-Steinhagen, K. Heck, A simple friction pressure drop correlation for two-phase flow in pipes, Chem. Eng. Process. 20 (1986) 297-308. 
[48] C. Lombardi, C.G. Carsana, A dimensionless pressure drop correlation for two-phase mixtures flowing upflow in vertical ducts covering wide parameter range, Heat Technol. 10 (1992) 125-141.

[49] B.A. Shannak, Frictional pressure drop of gas liquid two-phase flow in pipes, Nuc. Eng. Des. 238 (2008) 3277-3284.

[50] J.R. Thome, A. Cioncolini, Flow Boiling in Macro and Microchannels, Vol. 3, Set 1, in: Encyclopedia of Two-Phase Heat Transfer and Flow, World Scientific Publishing, Singapore, 2015.

[51] M.A. Woldesemayat, A.J. Ghajar, Comparison of void fraction correlations for different flow patterns in horizontal and upward inclined pipes, Int. J. Multiphase Flow 33 (2007) 347-370.

[52] A. Cioncolini, J.R. Thome, C. Lombardi, Unified macro-to-microscale method to predict two-phase frictional pressure drops of annular flows, Int. J. Multiphase Flow 35 (2009) 1138-1148.

[53] A. Cioncolini, J.R. Thome, C. Lombardi, Algebraic turbulence modeling in adiabatic gas-liquid annular two-phase flow, Int. J. Multiphase Flow 35 (2009) 580-596.

[54] A. Cioncolini, J.R. Thome, Algebraic turbulence modeling in adiabatic and evaporating annular two-phase flow, Int. J. Heat Fluid Flow 32 (2011) 805-817.

[55] A. Cioncolini, D. Del Col, J.R. Thome, An indirect criterion for the laminar to turbulent flow transition in shear-driven annular liquid films, Int. J. Multiphase Flow 75 (2015) 26-38.

[56] S. Kakaç, R. Shah, W. Aung, Handbook of Single-Phase Convective Heat Transfer, Wiley Publishing, USA, 1987.

[57] G.F Hewitt, N.S. Hall-Taylor, Annular Two-Phase Flow, Pergamon Press, UK, 1970. 

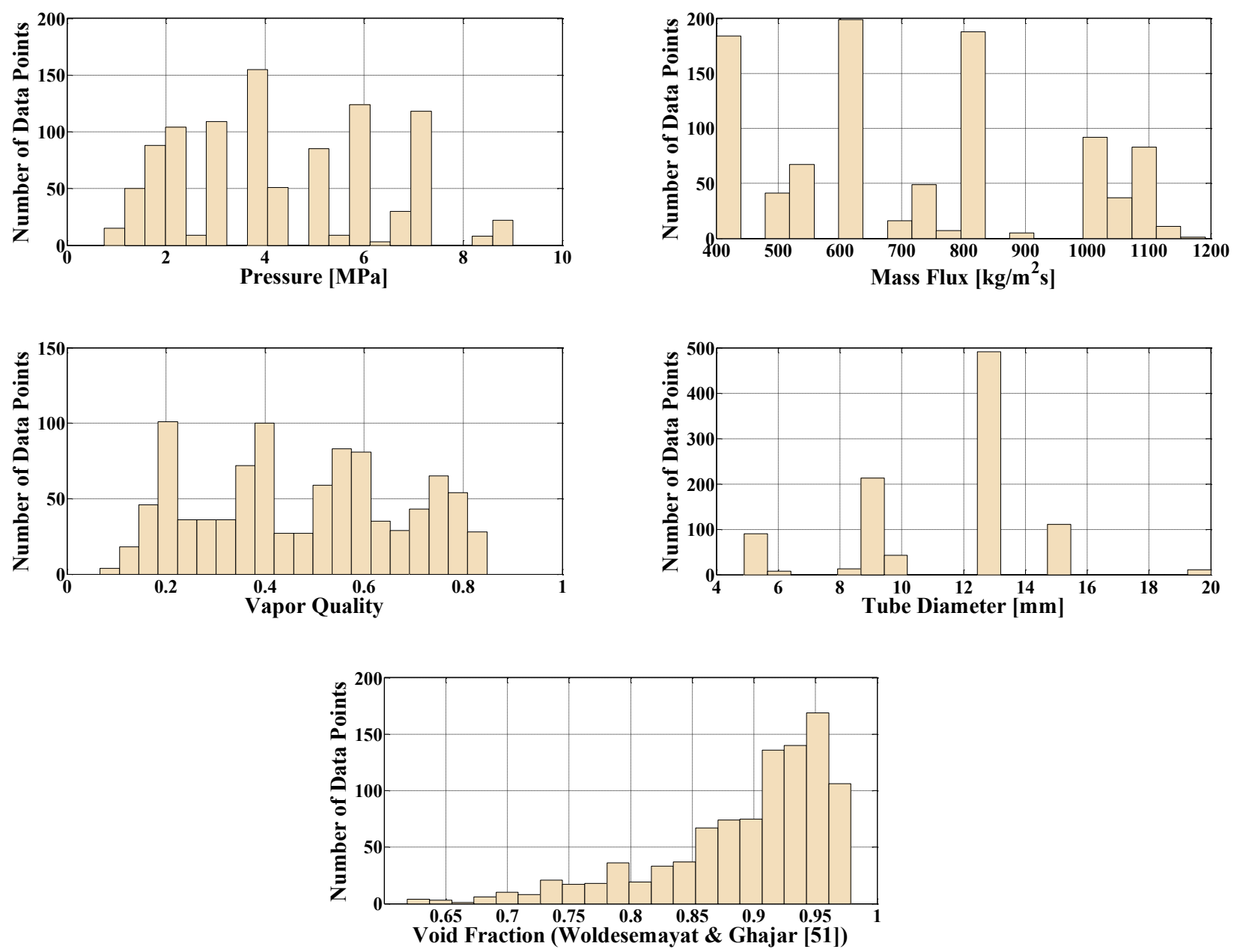

Fig. 1. Selected histograms describing the experimental databank in Table 1 (980 data points). 

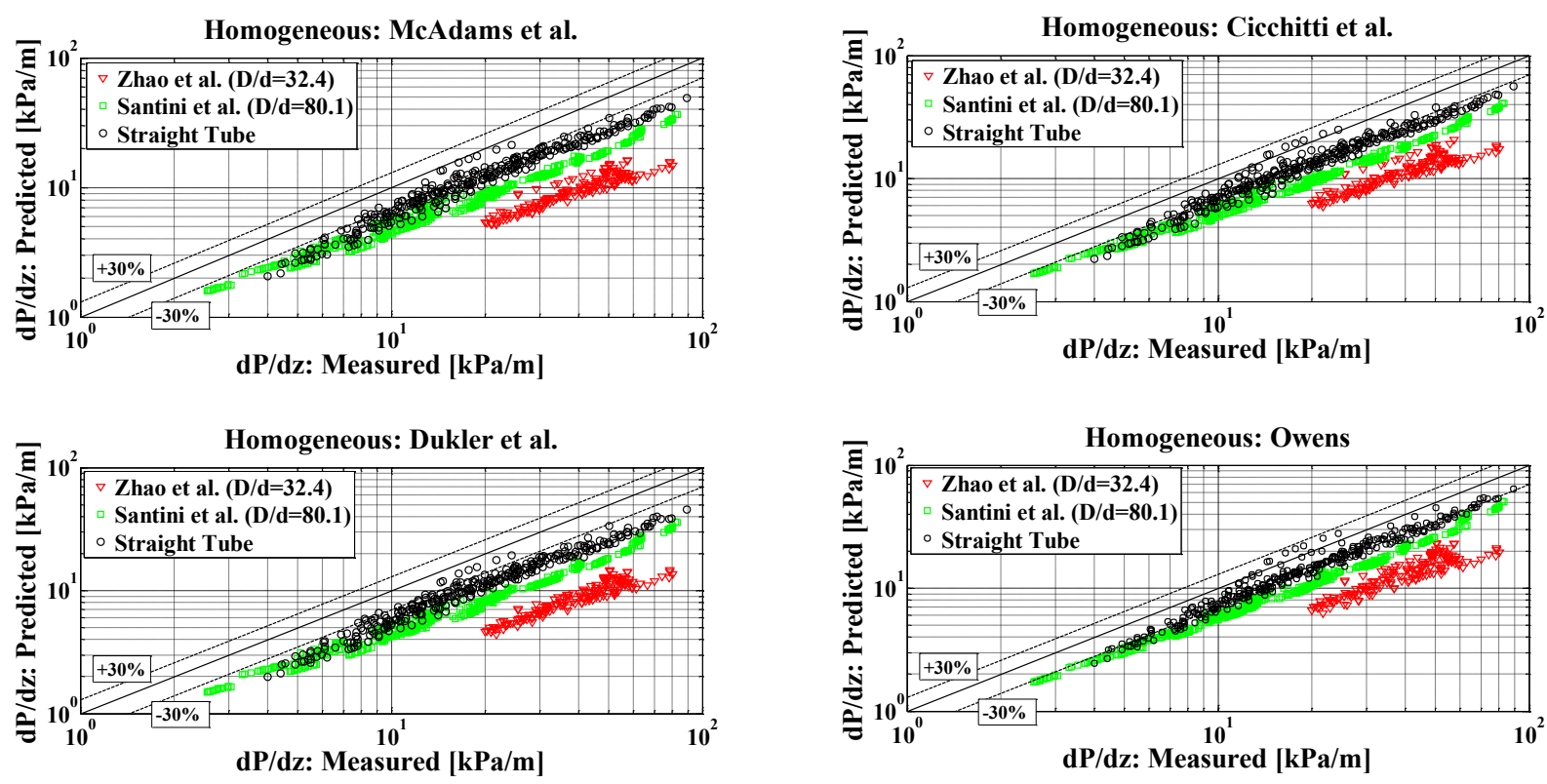

Fig. 2. Pressure gradient: predictions of straight tube correlations vs. measurements from Table 1. 

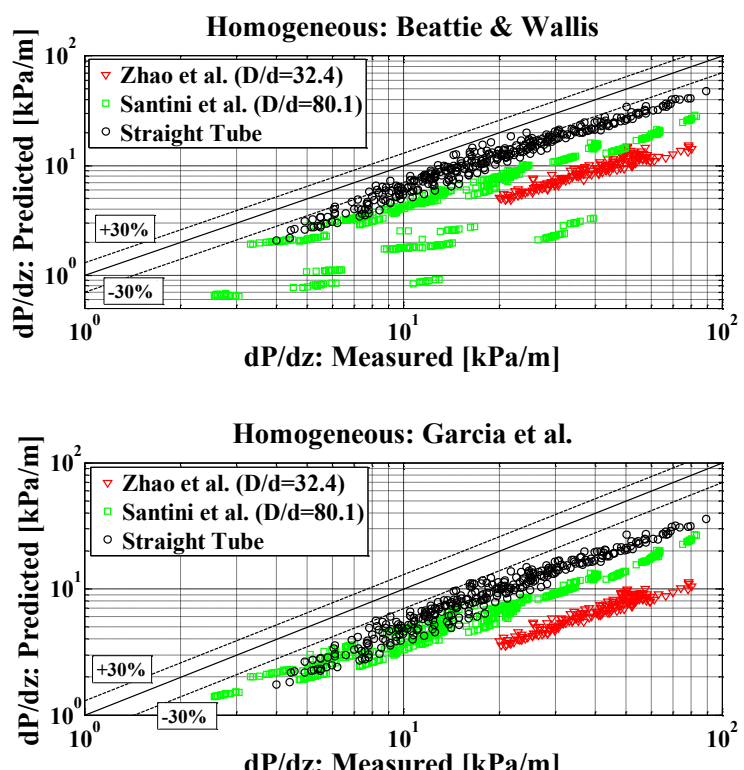

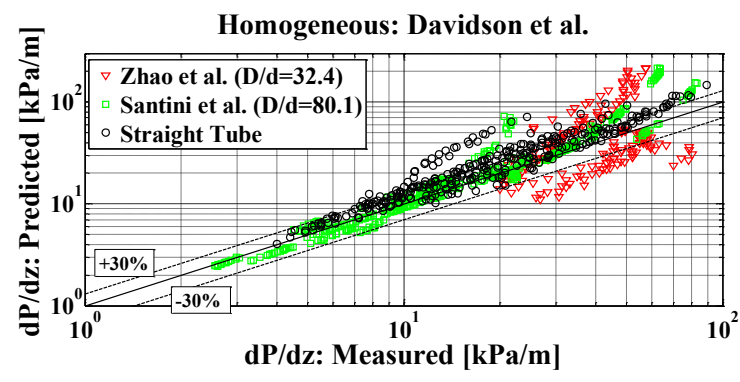

Homogeneous: Akers et al.

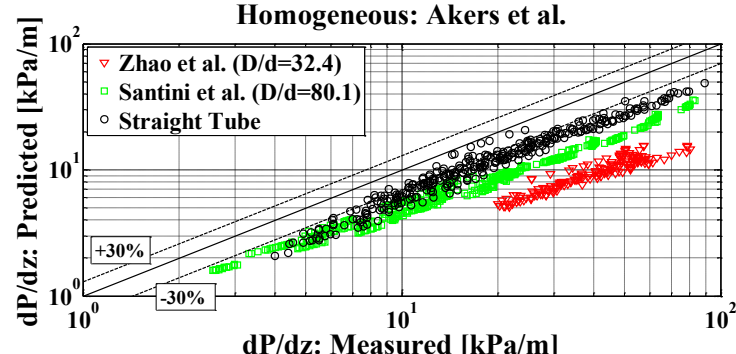

Fig. 3. Pressure gradient: predictions of straight tube correlations vs. measurements from Table 1. 

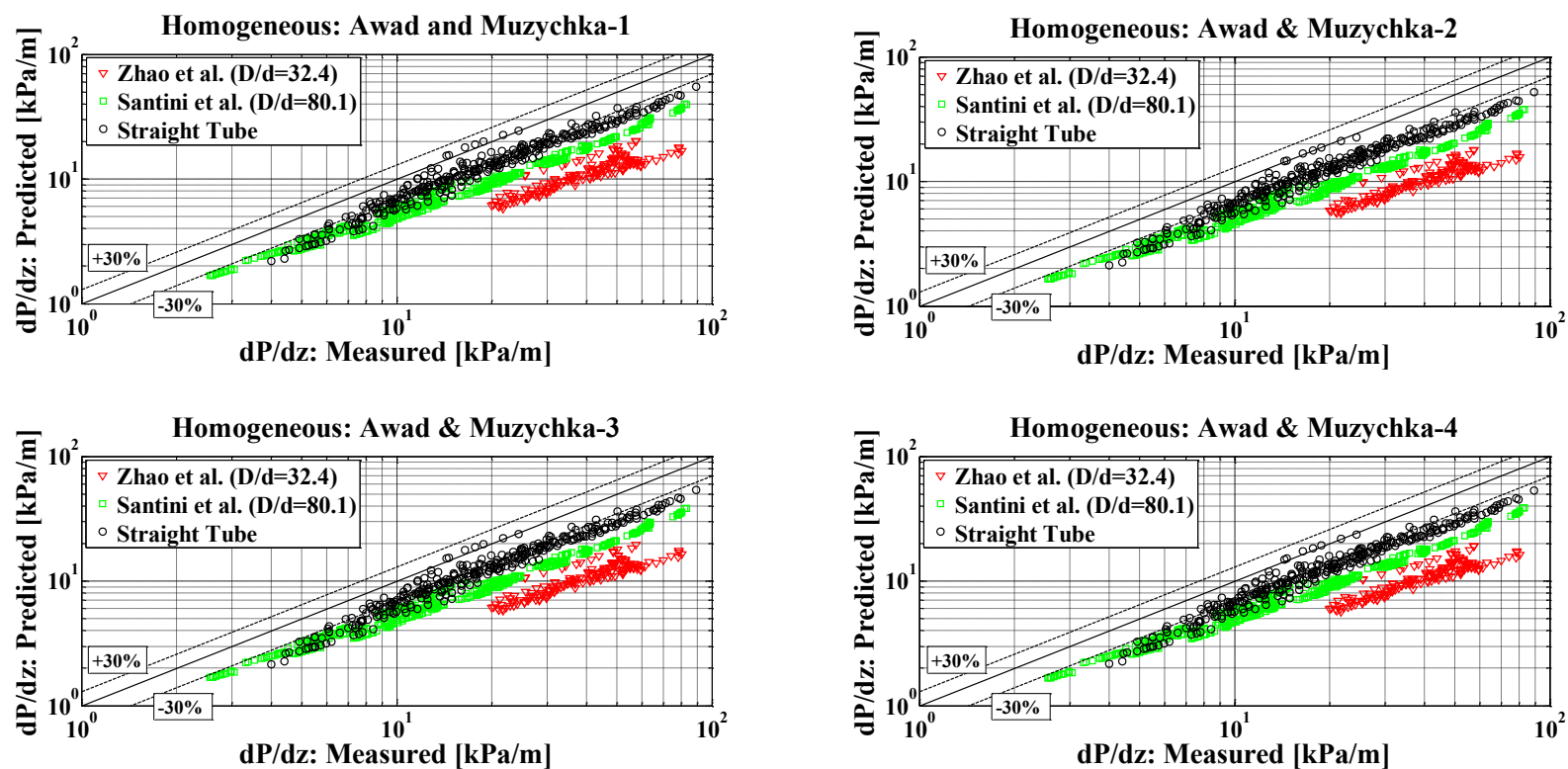

Fig. 4. Pressure gradient: predictions of straight tube correlations vs. measurements from Table 1. 

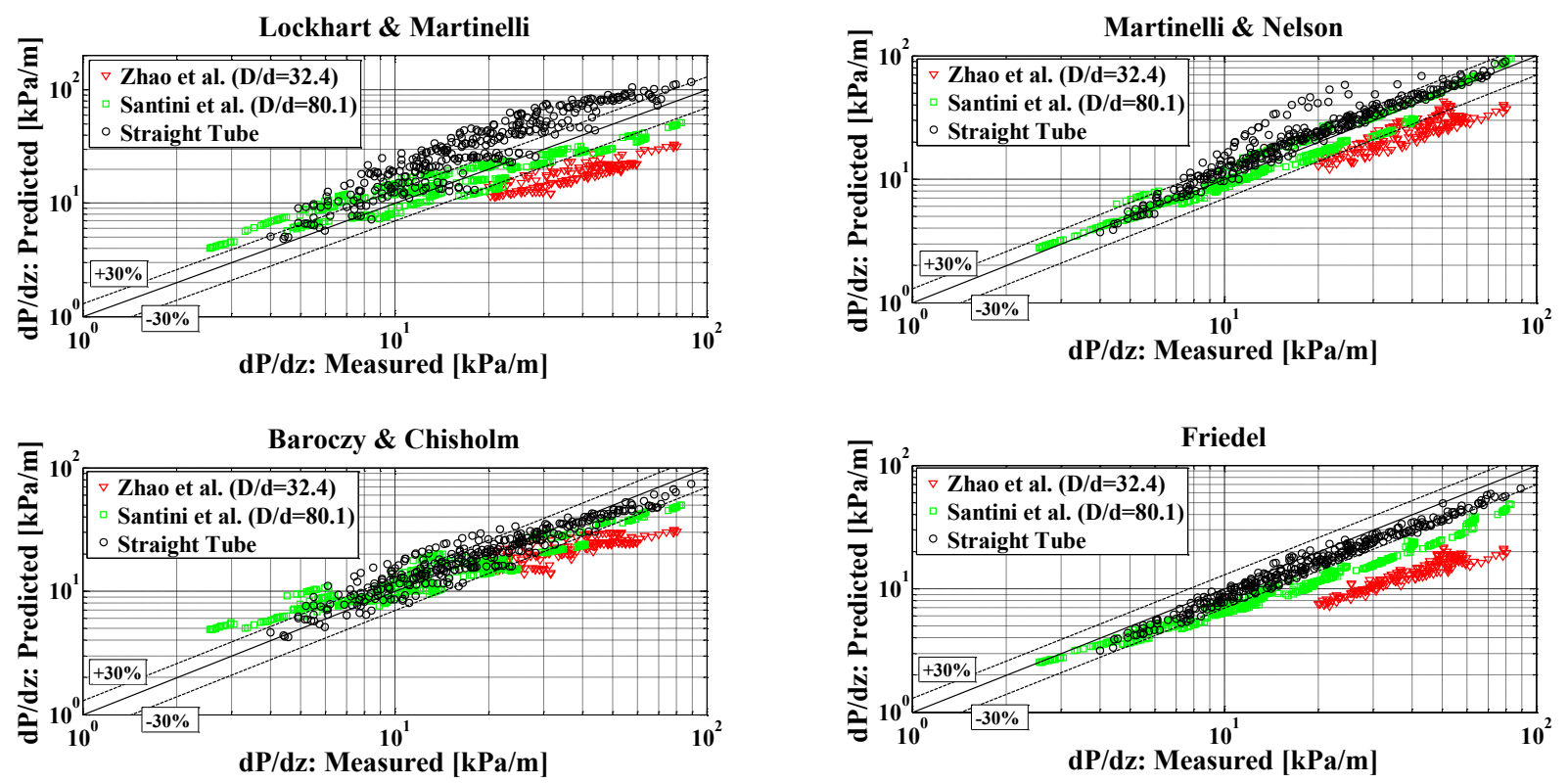

Fig. 5. Pressure gradient: predictions of straight tube correlations vs. measurements from Table 1. 


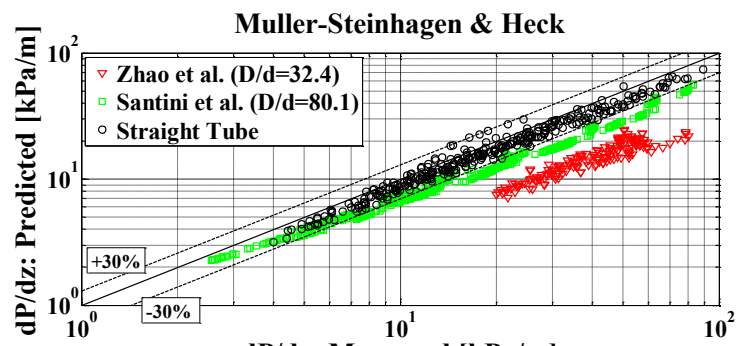

$\mathrm{dP} / \mathrm{dz}$ : Measured $[\mathrm{kPa} / \mathrm{m}]$

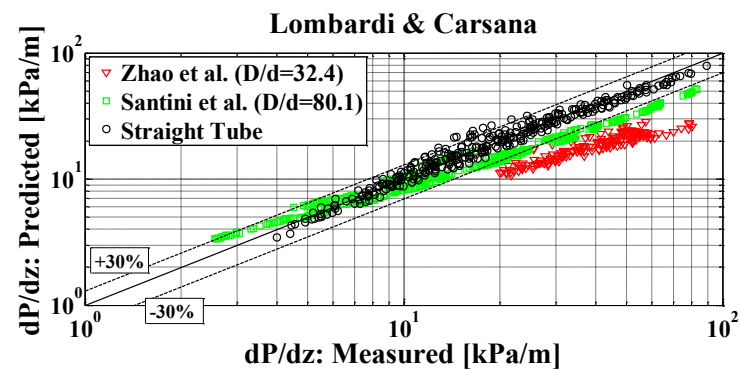

Shannak

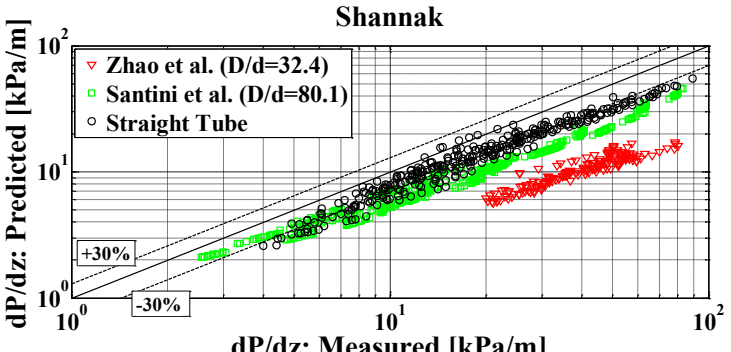

dP/dz: Measured [kPa/m]

Fig. 6. Pressure gradient: predictions of straight tube correlations vs. measurements from Table 1. 


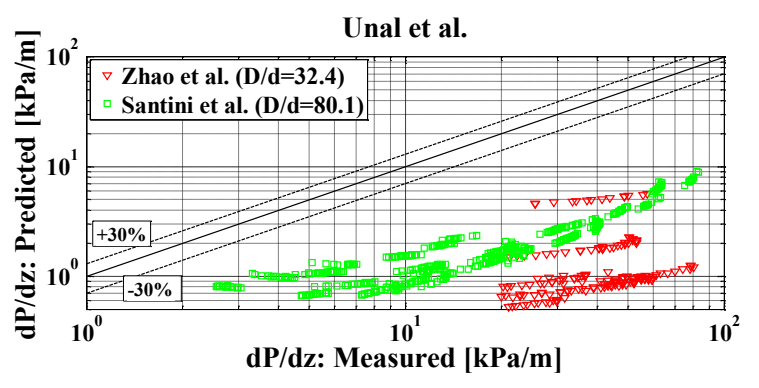

Bi et al.

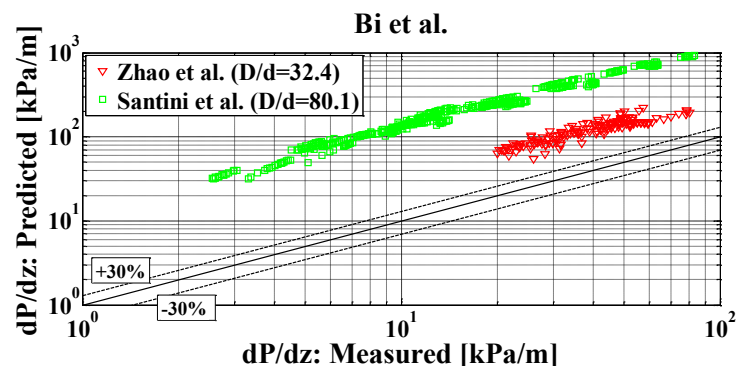

Ruffel

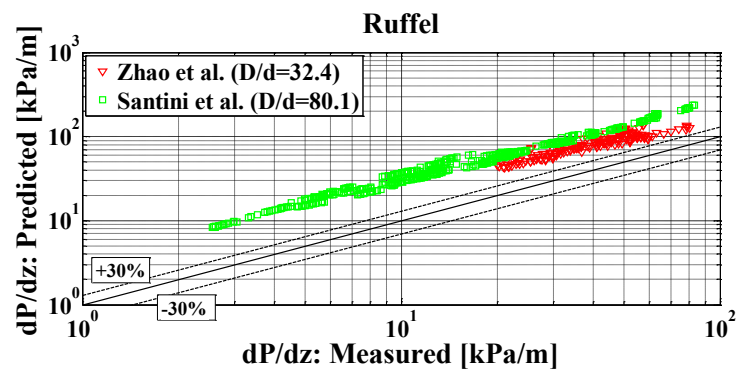

Zhao et al.

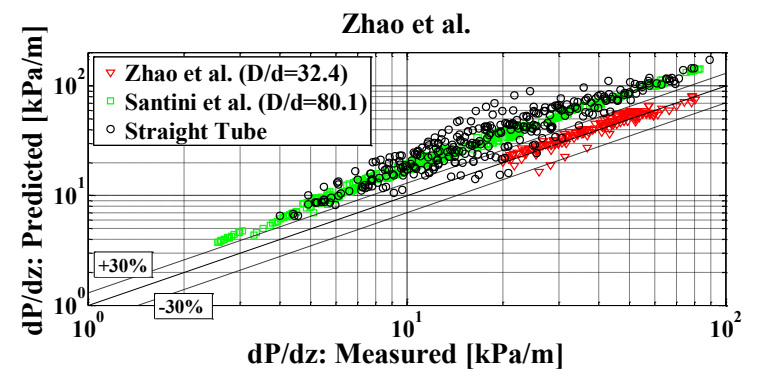

Guo et al.

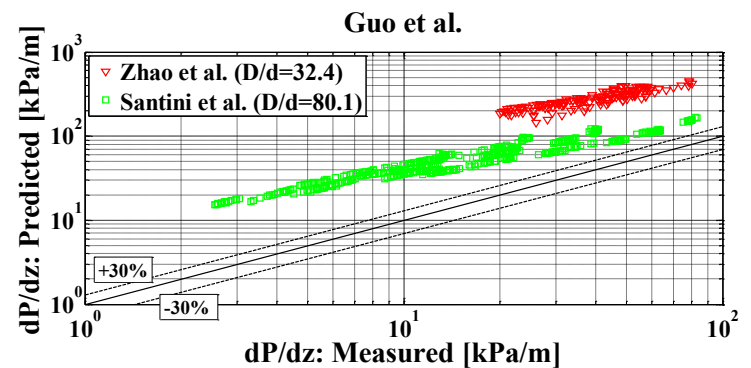

Santini et al.

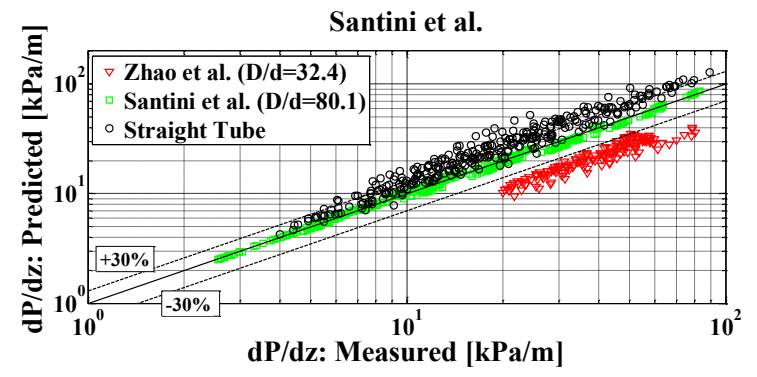

Fig. 7. Pressure gradient: predictions of helically coiled tube correlations vs. measurements from Table 1. 


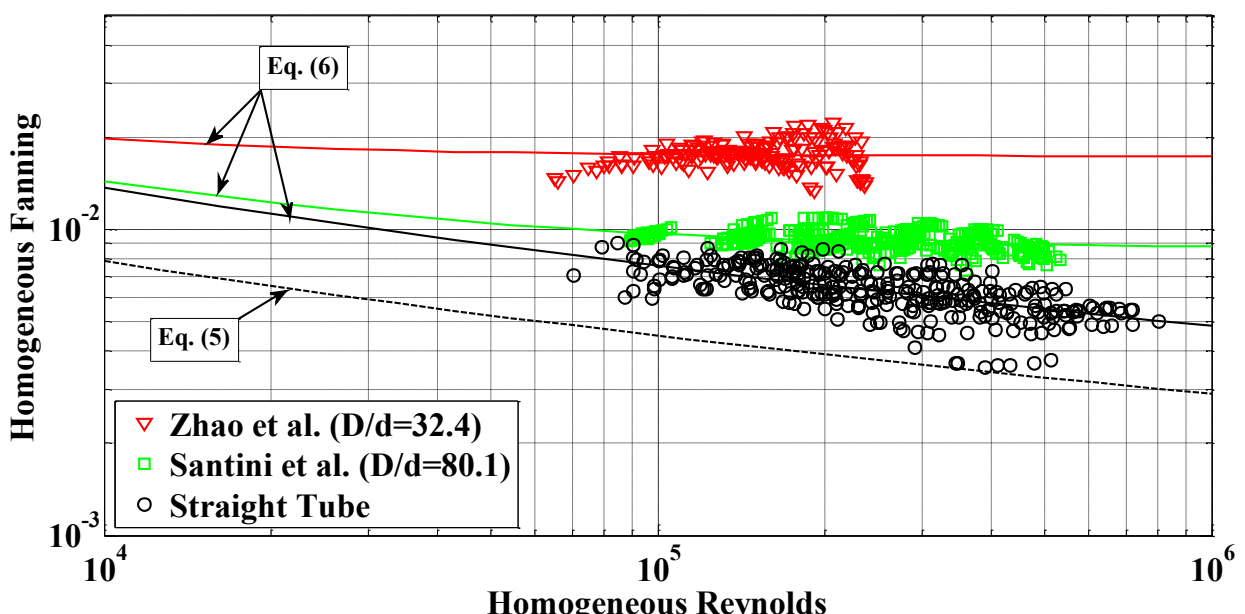

Fig. 8. Homogeneous Fanning friction factor for the data in Table 1 vs. homogeneous Reynolds number. 


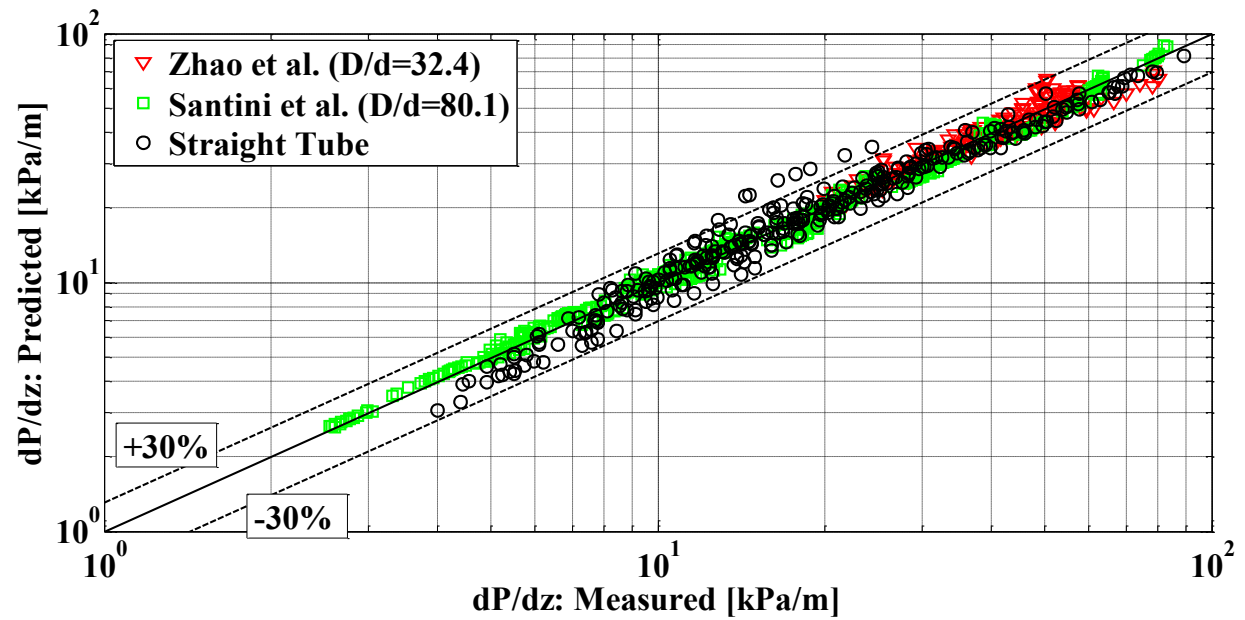

Fig. 9. Pressure gradient: predictions of the proposed correlation, Eqs. (1) and (6), vs. measurements from Table 1. 
Table 1.

Experimental pressure drop data bank

\begin{tabular}{lcccccccc}
\hline \multicolumn{1}{c}{ Reference } & $D(\mathrm{~mm})$ & $d(\mathrm{~mm})$ & $D / d$ & $P(\mathrm{MPa})$ & $G\left(\mathrm{~kg} / \mathrm{m}^{2} \mathrm{~s}\right)$ & $x$ & $q_{w}\left(\mathrm{~kW} / \mathrm{m}^{2}\right)$ & No. points \\
\hline Zhao et al. [20] & 292 & 9.0 & 32.4 & $0.75-3.0$ & $400-900$ & $0.11-0.82$ & $0-750$ & 168 \\
Santini et al. [23] & 1000 & 12.49 & 80.1 & $1.3-6.2$ & $410-820$ & $0.12-0.84$ & $90-230$ & 491 \\
Straight tube [32-34] & $\infty$ & $5.0-20.0$ & $\infty$ & $2.0-9.0$ & $498-1191$ & $0.07-0.85$ & 0 & 321 \\
\hline
\end{tabular}

Table 2.

Statistical comparison between pressure drop data from Table 1 and correlation predictions.

\begin{tabular}{|c|c|c|c|c|c|}
\hline & $(1)$ & $(2)$ & (3) & (4) & $(5)$ \\
\hline Homogeneous: McAdams et al. [35] & 52.5 & 52.5 & 0.7 & 3.4 & 45.9 \\
\hline Homogeneous: Cicchitti et al. [36] & 47.2 & 47.1 & 1.6 & 9.1 & 54.7 \\
\hline Homogeneous: Dukler et al. [37] & 55.6 & 55.6 & 0.0 & 1.1 & 38.2 \\
\hline Homogeneous: Owens [38] & 41.7 & 41.5 & 2.4 & 20.9 & 80.7 \\
\hline Homogeneous: Beattie and Whalley [39] & 59.7 & 59.7 & 0.6 & 3.5 & 33.2 \\
\hline Homogeneous: Davidson et al. [40] & 35.8 & -24.8 & 40.7 & 65.0 & 80.8 \\
\hline Homogeneous: Garcia et al. [41] & 62.7 & 62.7 & 0.0 & 0.0 & 17.1 \\
\hline Homogeneous: Akers et al. [42] & 52.7 & 52.7 & 0.6 & 3.5 & 45.8 \\
\hline Homogeneous: Awad and Muzychka [43] No. 1 & 48.1 & 48.0 & 1.4 & 7.5 & 52.9 \\
\hline Homogeneous: Awad and Muzychka [43] No. 2 & 50.1 & 50.1 & 0.8 & 5.6 & 49.6 \\
\hline Homogeneous: Awad and Muzychka [43] No. 3 & 48.9 & 48.9 & 1.3 & 7.1 & 51.6 \\
\hline Homogeneous: Awad and Muzychka [43] No. 4 & 49.1 & 49.0 & 1.1 & 6.4 & 51.3 \\
\hline Lockhart and Martinelli [24] & 46.2 & -15.7 & 17.3 & 37.0 & 59.0 \\
\hline Martinelli and Nelson [25] & 21.0 & 0.5 & 45.7 & 78.8 & 94.6 \\
\hline Baroczy [44]-Chisholm [45] & 27.1 & 4.8 & 32.3 & 60.5 & 88.6 \\
\hline Friedel [46] & 34.7 & 34.5 & 16.0 & 47.4 & 79.8 \\
\hline Müller-Steinhagen and Heck [47] & 32.1 & 31.5 & 18.9 & 49.6 & 82.9 \\
\hline Lombardi and Carsana [48] & 23.3 & 16.7 & 44.1 & 68.3 & 87.4 \\
\hline Shannak [49] & 43.7 & 43.7 & 2.9 & 23.9 & 71.1 \\
\hline Unal et al. [12] & 90.5 & 90.5 & 0.0 & 0.0 & 0.0 \\
\hline Zhao et al. [20] & 68.7 & -68.0 & 15.2 & 19.2 & 24.3 \\
\hline Bi et al. [26] & 939 & -939 & 0.0 & 0.0 & 0.0 \\
\hline Guo et al. [19] & 345 & -345 & 0.0 & 0.0 & 0.0 \\
\hline Ruffel [11] & 177 & -177 & 0.0 & 0.0 & 0.0 \\
\hline Santini et al. [23] & 20.7 & -2.5 & 56.9 & 64.9 & 89.1 \\
\hline Present study, Eqs. (1) and (6) & 7.3 & 0.7 & 90.9 & 99.1 & 99.5 \\
\hline
\end{tabular}

(1)-Mean absolute percentage error (\%): $\frac{100}{n} \sum_{1}^{n} \frac{\left|(d P / d z)_{\exp }-(d P / d z)_{c a l}\right|}{(d P / d z)_{\exp }}$

(2)-Mean percentage error (\%): $\frac{100}{n} \sum_{1}^{n} \frac{(d P / d z)_{\exp }-(d P / d z)_{c a l}}{(d P / d z)_{\exp }}$

(3)-Percentage of experimental data captured within $\pm 15 \%$

(4)-Percentage of experimental data captured within $\pm 30 \%$

(5)-Percentage of experimental data captured within $\pm 50 \%$ 